Mt Graham and the environment

SIR - I should like to comment on your report about legislation for Mt Graham's third telescope (Nature 379, 199; 1996).

Despite the perceptions of activists to the contrary, the inclusion of language authorizing the US Forest Service to proceed with the third telescope - on the site the service selected as having minimum environmental impact - was in no way at the expense of an HIV/AIDS testing programme for Native Americans. The language mentioned was in the Senate bill but not included in the House of Representatives bill. Before conference, the Senate agreed to accept the position of the House. This all occurred independently of the inclusion of $\mathrm{Mt}$ Graham language in the legislation.

Moreover, the Senate language provided no funding for the HIV/AIDS study, but simply expressed the Senate's interest in seeing a report issued. The Indian Health Service (IHS) has full authority to do the study without the Senate language. If telescope opponents are as concerned about this issue as they would have us believe, they would have been working with the IHS all along to address this matter. It appears that telescope opponents are principally interested in creating an issue.

The same is true of other topics. Most of the environmental evidence before the beginning of construction in 1989 and all the evidence since then shows that the observatory has negligible detrimental effect on the endangered red squirrel. This is simply a non-issue invented to try to stop the observatory.

Similarly, the concerns about Native American (Apache) use of the mountain have been propagated by essentially these same opponents of the observatory rather than by the tribe itself. Indeed, the previous tribal chairman felt compelled to write to the Forest Service to explain that these people did not represent the Apaches.

The bottom line remains the same. Opponents of the observatory continue to misuse environmental and cultural laws in order to stop a scientific project that, in itself, will have no significant negative impact on either the environment or on cultural practices.

Peter A. Strittmatter

Steward Observatory,

University of Arizona,

Tucson, Arizona 85721, USA

\section{Using placebos}

SIR - I pointed out earlier (Nature 375, 530; 1995 ) that because placebos are unregulated and have not been shown to be inert, an apparent positive, negative or null effect of a drug in a placebo-controlled trial could issue instead from a negative, positive or samedirection effect of the placebo. J. H. Schoemaker (Nature 377, 98; 1995) concedes the point, but believes it prudent to ignore this problem, because facing it might cost money.

Efforts to address the placebo problem need not be costly, and some might even save money. Focus groups could be convened to devise low-cost suggestions. Guidelines on what constitutes acceptable placebos could be developed. Journals could insist that all constituents of placebo and drug be named by weight. One or two placebo agents might be adopted as standards, and their effects examined in detail so that these effects might be adjusted for in analysis. Selected well-studied flavours and coatings could become standard for use with both drug and placebo, actually reducing costs by obviating the need to match the flavour and appearance of the placebo to each drug.

Schoemaker asserts that "in the worst case", if a drug is credited for effects it does not produce because "by chance" there had been negative effects of the placebo, "this may not be harmful". Yet it may be enormously harmful if the result influences clinical practice. In addition, it is naive to suppose that only by chance can a drug be falsely credited because of a deleterious placebo. Pharmaceutical companies currently determine the composition of placebos in trials of their own drugs; as billions of dollars may be at stake in the outcome, production of the 'inert' comparison agent by the drug company that manufactures the treatment drug under study represents a clear conflict of interest, particularly worrying in the absence of regulations, testing of placebo agents for inertness, or even a statement of the placebo composition in published journal articles. These concerns might be mitigated if there were formal regulations about placebo constituents and if production of placebos were removed from the hands of the company manufacturing the study drug.

Beatrice A. Golomb

Department of Medicine,

University of California, Los Angeles,

B-973 Louis Factor Building,

10833 Le Conte Avenue,

Los Angeles, California 90095-1736, USA

\section{Size matters}

SIR - Et al. wins Nobel Prize, said Hecht in 1977 (ref. 1). Nothing has changed - multiple co-authorship is the rule rather than the exception. How is the reader to sort out who really did the work, who really had the ideas that lead to a citation classic? Lewison and colleagues propose a fractional grading ${ }^{2}$, which allows a general analysis of a group of papers but does not disclose the true proportional contributions of multiple co-authors to a single paper.
We propose variable font point size as a solution. Briefly, author names will be listed as before, first authorship implying, as now, a major role in the work presented. Senior authors may, as now, run in the anchor position, thus emphasizing administrative success. Both their and other names will be further modified by setting each in a font size appropriate to their contribution. Smith's twofold greater effort will be rewarded by, for instance, 16 point compared to the 8 reaped by Jones . Font sizes

Smith, J. \& Jones, S. "Font point size and research contribution" J. unpubl. Res. 1, 2-3 (1996).

could vary up to fivefold, easily achieved on modern printers. Thus, scientists would no longer refer to their number of papers but to point size or even to their accumulated point scores, a truer measure of their own work.

It is possible to modify this system, for instance by italics or bold or underlined features. We suggest avoiding such subtleties until the size grading is fully accepted.

This new font point size system would not only help the real contributors but would also be a disincentive to those who were in fact minimal contributors, just added on for the ride - their names in tiny font point letters would show that size really matters.

\section{Eric P. Cohen}

Steven E. Mutsaers *

*to whom correspondence should be addressed at:

Department of Medicine,

The Rayne Institute,

University College London,

London WC1E 6JJ, UK

1. Hecht F. New. Engl.. J.. Med.. 296, 234 (1977).

2. Lewison G., Anderson, J. \& Jack, J. Nature 377, 671 (1995)

\section{Merely noise?}

SIR - The logic of Bill Amos's letter (Nature 379, 484; 1996) on 'chance findings' leads to a disturbing conclusion. We know there is a strong bias towards the publication of positive results. We also know that fewer than one in 20 studies are ever published in journals. Could it be that those studies accepted for publication in journals such as your own are merely Amos's chance findings? The logical conclusion is, sir, that your journal may be merely noise $(P<0.05)$.

Christopher Bulstrode

University of Oxford,

Nuffield Department of

Orthopaedic Surgery,

John Radcliffe 11 Hospital,

Oxford OX3 9DU, UK

\section{Correspondence}

Letters submitted for Correspondence should be typed, double-spaced, on one side of the paper only, or e-mailed to nature@nature.com 